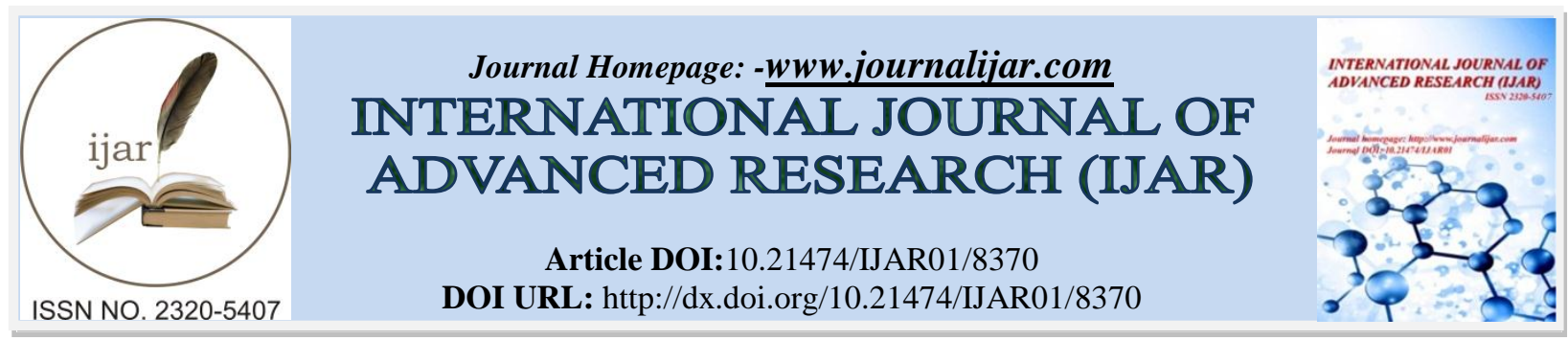

RESEARCH ARTICLE

\title{
INFLUENCE OF RESEARCH AWARENESS AND CULTURE TO THE LEVEL OFRESEARCH PRODUCTIVITY AMONG FACULTY MEMBERS OF A HIGHER EDUCATION INSTITUTION.
}

\author{
Eden C. Callo ${ }^{1}$ and Ma. Rona D. Sahagun ${ }^{2}$. \\ 1. Graduate Studies and Applied Research, Laguna State Polytechnic University, Philippines. \\ 2. College of Arts and Sciences, Laguna State Polytechnic University, Philippines.
}

\section{Manuscript Info}

Manuscript History

Received: 10 November 2018

Final Accepted: 12 December 2018

Published: January 2019

\section{Key words:-}

implementation, motivation, productivity, research awareness, research culture,

\section{Abstract}

This study assessed the influence of research awareness and culture on the research productivity among faculty members of Laguna State Polytechnic University, Philippines. Research designed used: descriptive-correlation, documentary analyses, and regression analysis. The research awareness among faculty members is high and the level of research culture in its qualitative aspects is true and highly evident. Research productivity is influenced by the faculty's level of research awareness and moderately influenced by research culture. Orientation on the university's research agenda, policies, thrusts and priorities; how are they implemented and disseminated motivate and encourage research productivity. Research constructive culture reveals that the research productivity becomes higher in an institution where there is a display of cooperation, a pleasant relationship and fulfillment of individual potentials. Constructive culture must be continued to benefit the faculty and the university.

Copy Right, IJAR, 2017, All rights reserved.

\section{Introduction:-}

One of the challenges faced by State Universities and Colleges (SUCs) in the Philippines is to generate, transfer and adopt technologies that would efficiently and effectively enhance productivity, alleviate poverty, and improve the country's state of competitiveness as stipulated in Commission in Higher Education (CHED) Memo no. 9 s. 2012. These can be achieved by enhancing and investing a huge amount of effort through research, development, and extension (NHERA 2, 2009; Olsson in Kearney, 2009; Japlos et. al., 2010; Bernales, 2011; Geronimo, 2014)

Research is a major function of Higher Education Institutions (HEIs) and is one of the major criteria in university ranking. The CHED formulates and recommends development plans, policies, priorities, and programs on higher education and research; hence, colleges and universities are mandated to produce researches and make their faculty members research capable and research-oriented.

Universities are the indispensable players in advancing scientific knowledge that leads to scientific breakthrough ... (Greenspan and Rosan 2003, Salmi 2011, Orale 2014). In the Academic Ranking of World University (ARWU), 60\% is allocated for research productivity (Rauhvargers, 2011) while the World University RankingTimes Higher Education allocated $20 \%$ of its point from research performance (Rauhvargers, 2011).

Global experiences now show that the changing agenda requires new ways of thinking about and doing research

Corresponding Author:-Eden C. Callo.

Address:-Graduate Studies and Applied Research, Laguna State Polytechnic University, Philippines. 
and development (Gonsalves, 2005).

SUCs are stratified into four levels based on the aggregated ratings along instruction, research, extension, and management of resources (CHED-DBM, 2003). The higher the level, the better is the quality of the SUCs (Orale, 2014). It can be deduced from the study of Goodal (2010) that the continued deterioration of quality maybe because of the institution's leader's qualification specifically on research competencies.

In the 2016 institutional evaluation known as SUC leveling, about 19\% belongs to Level 4 SUCs (the best SUCs in instruction, research, extension, and production) while about $44 \%, 25 \%$, and $12 \%$ belong to Level 3,2 , and 1 , respectively (CHED Memo \#12, s 2018).

Shamai and Kifir (2002) state that any higher education institutions worthy of its name must promulgate research and research culture which preserves its "formal and substantive right to be the gatekeeper".

Culture in research refers to the behavior of the faculty members required to fit in and meet expectations within the academic community. The research culture in this study was perceived in three dimensions as follows: constructive culture; passive/defensive; and aggressive/defensive.

Constructive cultures are characterized by norms for achievement, self-actualizing, humanistic-encouraging, and affiliative behaviors, which encourage members to interact with people and approach tasks in ways that will help them to meet their higher-order satisfaction needs.

Passive/Defensive cultures are characterized by approval, conventional, dependent, and avoidance norms, which encourage or implicitly require members to interact with people in ways that will not threaten their own personal security.

Aggressive/Defensive cultures encompass oppositional, power, competitive, and perfectionist norms, which encourage or drive members to approach tasks in forceful ways to protect their status and security.

The LSPU summarized its course of actions in meeting academic excellence and research productivity in its vision statement: Be recognized in our own area as a center of development before we are known globally offering programs at par with local and global universities. (De Vera, Annual Report, 2013). The University's research agenda is in consonance with the institutional, regional and national priorities of government agencies. Its mission is focused to be pro-actively generating relevant and innovative research outputs that transform people and communities towards a better quality of life (LSPU Annual Report, 2014). The university's agenda on institutionalizing research pointed out that it must conduct researches to address its mission to be one leading research center in the country by the year 2020. The R.O.S.E. (Resources, Operations, Stakeholders and Excellence \& Relevance) program explains that to explore for/or utilize untapped resources, academic operations should not be severely affected. Research \& Development (R\&D) activities should enhance learning and excellence in research. Research should be everybody's concern.

The researchers focused this study on the influence of the research awareness and culture on the research productivity among the faculty members of the Laguna State Polytechnic University System.

\section{Statement of the Problem:-}

This study aimed to answer the following questions:-

To what extent is the level of research awareness among faculty of Laguna State Polytechnic University System in terms of orientation, ethics, competence, priorities and relevance, funding and other resources, implementation, monitoring, evaluation and utilization of research, results/outputs, and publication \& dissemination?

Which research culture style best describes the Laguna State Polytechnic University System as perceived by the faculty members in terms of constructive; passive/defensive, and aggressive/defensive?

To what level is the qualitative research productivity of the faculty members in terms of technology trend, resource generation, the potential of academic personnel, auxiliaries, library holdings, and computer services?

Is the extent of research productivity singly or in combination, influenced by the level of research awareness, and 
moderatelyinfluenced by research culture among the faculty of LSPU?

Hypotheses:-

Based on the research questions, the following hypotheses were tested:

$\mathrm{HO}_{1}$. The level of research awareness does not significantly influence the research productivity of the faculty of the Laguna State Polytechnic University.

$\mathrm{HO}_{2}$. The extent of research productivity is not moderately influenced by the level of research culture among the faculty of the Laguna State Polytechnic University.

\section{Significance of the Study:-}

The results of this study would benefit the society in enhancing research culture and research capability of LSPU.

To provide the CHED with information about LSPU System.

The university administration to further enhance the Research Program and uplift and ensure a more effective program implementation. Through the findings of the study, the administrators would be aware of the problems faced by the faculty on conducting research. It may also serve as inspiration for new and old faculty members to pursue research.

\section{Research Framework:-}

The research framework is based on the literature review.

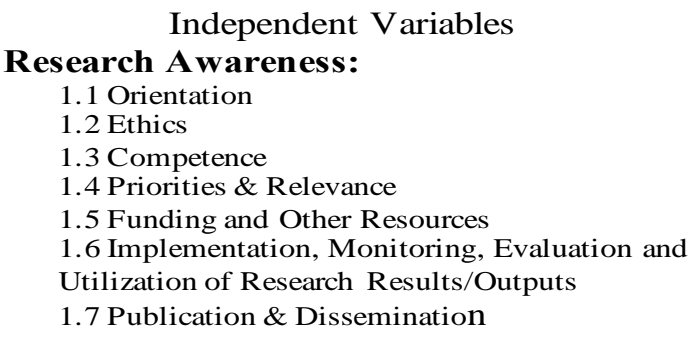

Moderating Variable

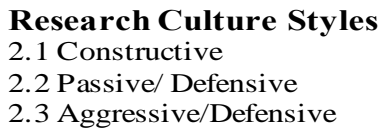

\author{
Dependent Variables \\ Research Productivity: \\ Qualitative Aspect \\ 1. Technology Trends \\ 2. Resource Generation \\ 3. Potentials of Academic \\ Personnel \\ 4. Auxiliaries, Library \\ Holdings and Computer \\ Services
}

Figure 1:-The relationship between research awareness and research productivity moderatingly influenced by research culture.

\section{Research Design:}

The study is a quantitative investigation using survey method.

\section{Respondents of the Study:-}

The respondents were: 203 (56\% of 372) regular faculty members randomly chosen from the four (4) campuses of the LSPU i.e. Los Baños th 69 (34\%); Sta. Cruz 61 (30\%); San Pablo 51 (25\%) and Siniloan 22 (11\%).

Most of the respondents belong to the 36-40 age bracket (27.09\%); females (66.50\%); married (74.88\%); respondents (47 or 17.73) have stayed 6-10 years of teaching; have master's degree(41 or $20.20 \%$ ), with Doctorate Degree (52 or $25.62 \%$ ); while the remaining faculty respondents are still working on their master's and doctoral degrees(110or 54.19\%); Catholic (148 or $72.91 \%$ ); Tagalog or born on the same region or province (181 or $89.16 \%$ ); teach more than 10 loads (104 or 51.23\%); majority (106 or 52.22\%) receive salary within the bracket of Php 20,000-29,000 (\$400-\$580) a month; and holding academic rank of Instructor I (70 or 67.96\%). There are six (6 or $2.96 \%)$ faculty members who had passed accreditation for a full-fledged professorship. 


\section{Research Instrument:-}

The study used a questionnaire based on the AACCUP (Accrediting Agency of Chartered Colleges and Universities in the Philipippenes, Inc.) Handbook for Accreditation (2004) and from varied references. The survey questionnaire has four parts: 1. age, gender, education, academic rank, ethnicity, religion, length of service, number of teaching loads handled, salary, and academic rank; 2. research awareness variables; 3 ) the research culture variables, and 4. research productivity in qualitative aspects. For measures of research productivity in quantitative aspects included were numbers of researches conducted and published and a number of services rendered as a professional expert.

The Likert scale of 1-5 was used to identify the perceived levels of research awareness, research culture, and research productivity. The AACCUP instrument for institutional accreditation was adopted with some modifications.

\section{Statistical Treatment of Data:-}

The data were analyzed using SPSS v.20 for Windows PC. The factor analysis was utilized to cull the indicators from the variables of research awareness, research culture and qualitative aspects of research productivity that would not significantly influence the research productivity. Extracting method using the principal component analysis marked the extraction values greater than .600 as significant predictors. The inferential statistics of multiple regression analysis was used to determine whether the extent of research productivity, singly or in combination is not influenced by the perceived research awareness and research culture among the faculty of Laguna State Polytechnic University.

\section{Results:-}

\section{Factor Analysis:-}

The results of factor analysis for Research Awareness identified inclusion of all 70 items in seven major independent variables and no item was deleted from this analysis. The School Culture variables with all its 30 item indicators were not culled, thus retained for further analysis in this study. The results of factor analysis for research productivity for qualitative measures identified the 40 -item indicators and further retained for further analysis.

\section{Findings:-}

Question \#1. To what extent is the level of research awareness among faculty of Laguna State Polytechnic University System?:-

In this study, research awareness is the independent variable which encompasses the importance of research as an important responsibility among faculty members of HEIs. They must exhibit evidences of research productivity together with other factors that contribute to the process.

Table 1:-Mean and standard deviation on the perceived level of research awareness

\begin{tabular}{|l|c|c|c|c|}
\hline Research Components & Mean & SD & Rank & Description \\
\hline 1.1 Orientation & 3.82 & .86 & 3 & Very Satisfactory \\
\hline 1.2 Ethics & 3.98 & .76 & 1 & Very Satisfactory \\
\hline 1.3 Competence & 3.84 & .79 & 2 & Very Satisfactory \\
\hline 1.4 Priorities \& Relevance & 3.80 & .86 & 4 & Very Satisfactory \\
\hline 1.5 Funding and Other sources & 3.60 & 1.29 & 6 & Very Satisfactory \\
\hline $\begin{array}{l}\text { Utilization of Research Results/ Outputs } \\
\text { 1.7 Publication and Dissemination }\end{array}$ & 3.72 & .86 & 5 & Very Satisfactory \\
\hline Overall & 3.57 & .94 & 7 & Very Satisfactory \\
\hline
\end{tabular}

LEGEND: N=203, $M$ values not shown on this table are statistical descriptives that are not included due to limited space. (4.21 - 5.00) Excellent (3.41 - 4.20) Very Satisfactory (2.61 - 3.4) Satisfactory (1.81-2.60) Fair (1.00 - 1.80) Poor

The findings reveal that the overall level of research awareness among faculty members of the LSPU on variables of research components (Table 1$)$ is very satisfactory, $(\mathrm{M}=3.76)$. The faculty members are highly aware that they are sufficiently knowledgeable and competent about the components of the university research agenda, thrusts and priorities, research paper and thesis, but are least highly aware of orientation on how the project budget is allocated and utilized.

Ethics in research is perceived to be very satisfactory $(\mathrm{M}=3.98)$ as the faculty members are highly aware on the 
significance of the university's effort in providing guidelines in reviewing, evaluating, and establishing enforcement mechanisms to ensure ethical implications in research.

The level of research competence(Table 1) among faculty members is generally perceived asvery satisfactory $(\mathrm{M}=3.84)$ having been highly aware that the manpower must be strengthened to conduct serous research undertakings related to their fields. The research component awareness on priorities and relevance is generally perceived asvery satisfactory, $(\mathrm{M}=3.80)$ having been highly aware that the university's research agenda are in consonance with the regional and national priorities of government agencies like the Department of Science and Technology, National Economic Development Authority, and CHED- National Higher Education Research Agenda.

Further, the faculty members' level of awareness on funding and other sources is very satisfactory (M=3.60). Faculty respondents are highly aware that general university funds give universities carrying out researches full freedom to allocate funds within their institutions. The level of awareness on research in terms of implementation, evaluation, and utilization of research outputs is perceived to be very satisfactory $(\mathrm{M}=3.72)$. There is high awareness in the process of implementing an efficient and effective research development program and measurement criteria. Faculty respondents' level of awareness on publication and dissemination is very satisfactory $(\mathrm{M}=3.57)$ knowing that the institution has approved and copyrighted research journals.

\section{Question 2:-Which research culture best describes the Laguna State Polytechnic University System as perceived by the faculty members?:-}

Research culture reflects the values, ideals, and beliefs about research within the LSPU academic community. It could be an aggressive/defensive culture where faculty members are trying to be noticed and do things perfectly; the environment is competitive and people tend to be critical of others. Faculty working in a passive culture is encouraged to do what they're told, keep out of trouble and avoid being in the wrong place at the wrong time. Faculty who are encouraged to strive, excel, experiment, learn and grow, support and help each other and build relationships work in a constructive culture.

Table 2:-Mean and SD on the level of research culture among the facultymembers of LSPU.

\begin{tabular}{|c|c|c|c|c|}
\hline Culture & Mean & $\mathrm{SD}$ & Rank & Description \\
\hline 1. Constructive & 3.74 & .81 & 1 & Highly Evident \\
\hline 2. Passive/Defensive & 3.65 & .86 & 2 & Highly Evident \\
\hline 3. Aggressive/Defensive & 3.62 & .85 & 3 & Highly Evident \\
\hline Overall & 3.67 & .84 & & Highly Evident \\
\hline
\end{tabular}

LEGEND: $N=203, M$ values not shown on this table are statistical descriptives that are not included due to limited space. (4.21-5.00) Very true/ Very Highly Evident (3.41 - 4.20) True/Highly Evident (2.61 - 3.4) Somewhat true/ Evident (1.81 - 2.60) Untrue/Moderately Evident (1.00 - 1.80) Very untrue/Not Evident

Table 2 reveals that the level of research culture in all three styles is highly evident in the LSPU system. The findings reveal that the LSPU research culture is constructive.

Most of the faculty members perceived all the indicators of the research cultures of the university "true of them/true of the university". Faculty members "are encouraged to be in communication with their co-workers, and work as a team, rather than only as individuals" $(\mathrm{M}=3.86)$. There is a supportive climate in the LSPU system while faculty members "cooperate with others, reflect an interest in developing and sustaining pleasant relationships, and share thoughts and feelings making others feel part of things" $(\mathrm{M}=3.63)$ and suggests there is still a need to be as one and faculty member should work as one.

The perceived level of research culture in terms of passive style is true of them, $(M=3.65)$. Faculty members believe they must interact with people in ways that will not threaten their own security and they avoid interpersonal conflict, $(\mathrm{M}=3.81)$ while at the same time experiencing a lot of unresolved conflict and turnover and are reported to have lower levels of motivation $(\mathrm{M}=3.53)$.

Lastly, the perceived level of research culture in terms of aggressive/ defensive style, faculty members disclose that this culture is true of them, $(M=3.62)$. Faculty members need to sustain results, equate self-worth with the attainment of extremely high standards, and place excessive demands on themselves and others and the least to compete with others. 
Question \#3: To what level is the qualitative research productivity of the faculty members be described?:Research Productivity refers to the capacity of the faculty members of LSPU in conducting researches, publishing articles, action researches or studies either in the local, national or international level, or being given assignments as co-author, adviser, thesis panelist or consultant either to co-faculty or student researchers.

Table 3:-Mean and SD on the level of qualitative aspects of research productivity.

\begin{tabular}{|c|c|c|c|c|}
\hline Qualitative Aspects & Mean & SD & Rank & Description \\
\hline 1. Technology Trends & 3.64 & .84 & 4 & Observed to a great extent ( $61 \%$ to $80 \%$ of the time) \\
\hline 2. Resource Generation Program & 3.67 & .84 & 3 & Observed to a great extent ( $61 \%$ to $80 \%$ of the time) \\
\hline 3. Potential of Academic Personnel & 3.82 & .77 & 1 & Observed to a great extent ( $61 \%$ to $80 \%$ of the time) \\
\hline $\begin{array}{l}\text { 4. Auxiliaries, Library Holdings } \\
\text { \&Computer Services }\end{array}$ & 3.74 & .82 & 2 & Observed to a great extent ( $61 \%$ to $80 \%$ of the time) \\
\hline Overal & 3.72 & .82 & & Observed to a great extent ( $61 \%$ to $80 \%$ of the time) \\
\hline
\end{tabular}

LEGEND: $\mathrm{N}=203, \mathrm{M}$ values not shown on this table are statistical descriptives that are not included due to limited space. $(4.21-5.00)$ Observed to a very great extent/ $81 \%$ to $100 \%$ of the time $(3.41-4.20)$ Observed to a great extent/ $61 \%$ to $80 \%$ of the time (2.61 - 3.4) Observed to a moderate extent/ $41 \%$ to $60 \%$ of the time $(1.81-2.60)$ Observed to a less extent/ $21 \%$ to $40 \%$ of the time $(1.00-1.80)$ observed poorly/ $0 \%$ to $20 \%$ of the time

The data (Table 3) reveal that the level of research productivity among the faculty members of the university is generally observed to a great extent $(\mathrm{Mean}=3.72)$. Rank1, the potentials of academic personnel to research productivity are observed to a great extent, $(\mathrm{M}=3.82)$, which may indicate that the university key officials appoint qualified personnel for research work.

On the other hand, the level of research productivity on auxiliaries, library holdings, and computer services is observed to a great extent, (M=3.74, Rank 2).

The level of productivity in terms of resource generation is observed to a great extent, $(M=3.67)$ and ranked 3rd.

Table 3 further shows that the level of observation on technology trends is to a great extent which is $81-100 \%$ most of the time, $(M=3.64)$, ranked 4 in the research productivity measure. The lowest observation shows the indicator "technology-generated research in foods, beauty products, socio-educational research implies that LSPU is still developing its productivity in terms of technological aspects and still needs to produce researches with outputs that can benefit the system and the community.

In summary, the overall perceptions of the faculty-respondents regarding the qualitative level of research productivity can be interpreted as observed to a great extent or $61 \%$ to $80 \%$ extent of compliance of the time.

Question \#4: To what level is the quantitative research productivity of the faculty members be described?:The research productivity of the faculty can be described quantitatively in terms of the number of assignments as author, co-author, and adviser; provider of expert advice professionally and the number of conducted professional activities that are part and parcel of a research career.

From the academic year 2013-2017, the faculty members presented a total of 362types of research, data being presented in Table 4. The result implies that the researches are only 14\% of the expected total number. The greatest turnout is at the local level which can be attributed to the number of hours to conduct either a small- or large-scale research. However, as the university requires research outputs from the faculty being presented internationally, there is quite a few (14 with 42 credits) having attempted to be achieved.

Table 4:-Quantitative indicators on research productivity of the faculty members.

\begin{tabular}{|l|c|c|c|c|}
\hline \multicolumn{1}{|c|}{ Indicators } & Local & National & International & \multirow{2}{*}{ Overall } \\
\cline { 2 - 4 } & $(\mathrm{x} 1)$ & $(\mathrm{x} 2)$ & 99 & \\
\hline No. of researches presented & 181 & 82 & 42 & \\
\hline No. of published articles & 91 & 28 & & \\
\hline No. of Assignments as: & & & & \\
\hline as author & 75 & & & 75 \\
\hline as co-author & 111 & & & 111 \\
\hline as adviser & 587 & & & 587 \\
\hline
\end{tabular}




\begin{tabular}{|c|c|c|c|c|}
\hline No. of Consultancy & & & & \\
\hline to co-faculty & 81 & & & 81 \\
\hline to student researchers & 1305 & & & 1305 \\
\hline No. of Assignments as Panelist & 1796 & & & 1796 \\
\hline Awards and Recognition Received & 26 & 26 & 12 & 64 \\
\hline
\end{tabular}

As to published articles, the highest number of published articles has transpired in the local level with 91 credits, national with 28 credits while in the international, 42 credits. The number of assignments as consultants to cofaculty is 81 while that of consultancy to student researchers is 1305 .

With regard to the number of assignments, the highest credit is 587 as an adviser, 111 as co-author and 75 as an author. The number of assignments as thesis panelist numbered 1796 faculty researchers. As to awards and recognition, the faculty respondents received the same number of awards (26) in both the local and the national level and 12 in the international level.

Testing the Influence of Research Awareness on Research Productivity:-

Question 5:-Is the extent of research productivity, singly or in combination influenced by the level of research awareness among faculty of Laguna State Polytechnic University System?:-

The first hypothesis $\left(\mathrm{HO}_{1}\right)$ test the influence of research awareness on the research productivity of faculty members.

The test of correlation was primarily made to determine if there is a significant relationship between variables in research awareness and research productivity. Results reveal significance at $(r>.70, p<.01)$.

Further, the regression analysis was used to identify which factors of research awareness significantly influence research productivity, and further regressed if the research productivity among faculty members may be moderately influence by the research culture in the academic environment.

The following tables present the results and discussions.

Table 5:-Influence of Research Awareness on Research productivity.

\begin{tabular}{|c|c|c|c|c|}
\hline \multirow{3}{*}{$\begin{array}{l}\text { Independent Variable } \\
\text { (Research Awareness) }\end{array}$} & \multicolumn{4}{|c|}{$\begin{array}{c}\text { Dependent Variable } \\
\text { (Research Productivity) }\end{array}$} \\
\hline & $\begin{array}{l}\text { Technology } \\
\text { Trends }\end{array}$ & $\begin{array}{c}\text { Resource } \\
\text { Generation }\end{array}$ & $\begin{array}{l}\text { Potential of } \\
\text { Academic } \\
\text { Personnel }\end{array}$ & $\begin{array}{c}\text { Auxiliaries, Library } \\
\text { Holdings, and Computer } \\
\text { Services }\end{array}$ \\
\hline & $\beta$ & $\beta$ & $\beta$ & B \\
\hline Orientation & & $.167 * *$ & $.166^{* * *}$ & \\
\hline Ethics & & & & \\
\hline Competence & & & & \\
\hline Priorities \& Relevance & & & & \\
\hline Funding \&Other Resources & $.223 * *$ & & & $.189 * *$ \\
\hline $\begin{array}{l}\text { Implementation, Monitoring, Evaluation } \\
\text { \& Utilization of Research Results/Output }\end{array}$ & $.292 * *$ & $.339 * *$ & $.479 * *$ & $.296 * *$ \\
\hline Publication \& Dissemination & $.263 * *$ & $.254 * *$ & $.196 * *$ & $.293 * *$ \\
\hline $\mathrm{R}-$ Square & .512 & .452 & .571 & .515 \\
\hline Adjusted R Square & .504 & .443 & .564 & .507 \\
\hline F-value & 69.533 & 54.652 & 88.234 & 70.318 \\
\hline Significance & $.000^{\mathrm{d}}$ & $.000^{\mathrm{d}}$ & $.000^{\mathrm{d}}$ & $.000^{\mathrm{d}}$ \\
\hline Durbin-Watson & 1.883 & 1.955 & 1.835 & 1.941 \\
\hline
\end{tabular}

Legend: $\mathrm{N}=203$, * Significant at $\mathrm{p}<.05 \quad * *$ Significant at $\mathrm{p}<.01$

The regression analysis reveal data (Table 5) indicating that the research productivity in its qualitative aspects accounts for the $50 \%$ of the variance in technology trends (adjusted $\mathrm{R}^{2} 0.504$ ). The F statistics for the adjusted $\mathrm{R}^{2}$ is 69.533 and the associated $\mathrm{p}$-value is .000 . It indicates that $\mathrm{p}<.05$; therefore, a statistically significant relationship exists between technology trends and research awareness at the 95.0 percent confidence level. The awareness of faculty members on funding and other resources variable $(\beta=0.223, p<.01)$; implementation, monitoring, evaluation and utilization of research results/output variable $(\beta=0.292, \mathrm{p}<.01)$; and publication and dissemination variable $(\beta$ $=0.263, \mathrm{p}<.01)$ are also influencers of research productivity in technology trends. Awareness of the implementation 
has the strongest positive influence among the three. The Durbin-Watson test $(1.883<2.00)$ points out that the extracted parameters are not the only possible explanations for the development of the item research awareness. Faculty members are informed on the research agenda and polices, research development program, and all the guidelines postulated in the research manual of the university.

The regression results (Table 5)further indicate that the research productivity in its qualitative aspects accounts for the $44.3 \%$ of the variance in resource generation (adjusted $\mathrm{R}^{2} 0.443$ ). The F statistics for the adjusted $\mathrm{R}^{2}$ is 54.652 and the associated $\mathrm{p}$-value is .000 . It indicates that $\mathrm{p}<.05$; therefore, a statistically significant relationship exists between resource generation and research awareness at the 95.0 percent confidence level. Further, there are two research awareness variables that have positive influences on the research productivity of the faculty members of the LSPU namely: research orientation $(\beta=0.167, \mathrm{p}<.01)$; (implementation, monitoring, evaluation and utilization of research results/output variable $(\beta=0.339, \mathrm{p}<.01)$; and publication and dissemination variable $(\beta=0.254, \mathrm{p}<.01)$. Awareness ofthe implementation has the strongest positive influence among the two. The Durbin-Watson test (1.955 $<2.00$ ) points out that the extracted parameters are not the only possible explanations for the development of the item research awareness.

The data indicate that the research productivity accounts for the $56.4 \%$ of the variance in the potential of academic personnel (adjusted $\mathrm{R}^{2}$ 0.564). The F statistics for the adjusted $\mathrm{R}^{2}$ is 88.234 and the associated p-value is .000 . It indicates that $\mathrm{p}<.05$; therefore, a statistically significant relationship exists between academic personnel potentials and research awareness at the 95.0 percent confidence level. There are three research awareness variables that have positive influences on the research productivity of the faculty members of LSPU namely: research orientation $(\beta$ $=0.166, \mathrm{p}<.01)$; implementation, monitoring, evaluation and utilization of research results/output variable $(\beta=0.479$, $\mathrm{p}<.01)$; and publication and dissemination variable $(\beta=0.196, \mathrm{p}<.01)$. Awareness of the implementation has the strongest positive influence among the three. The Durbin-Watson test $(1.835<2.00)$ points out that the extracted parameters are not the only possible explanations for the development of the item research awareness. However,

The data resulted from the regression analysis indicate that the research productivity in its qualitative aspects accounts for the $50.7 \%$ of the variance in auxiliaries, library holdings and computer services (adjusted $\mathrm{R}^{2} 0.507$ ). The F statistics for the adjusted $\mathrm{R}^{2}$ is 70.318 and the associated $\mathrm{p}$-value is .000 . It indicates that $\mathrm{p}<.05$; therefore, a statistically significant relationship exists between technology trends and research awareness at the 99.0 percent confidence level. There are three research awareness variables that have positive influences on the research productivity of the faculty members. The funding and other resources variable $(\beta=0.189, \mathrm{p}<.01)$; implementation, monitoring, evaluation and utilization of research results/output variable $(\beta=0.296, p<.01)$; and publication and dissemination variable $(\beta=0.293, \mathrm{p}<.01)$. Awareness of the implementation has the strongest positive influence among the three. The Durbin-Watson test $(1.941<2.00)$ points out that the extracted parameters are not the only possible explanations for the development of the item research awareness.

The positive influences imply that with the increase in research awareness, there is the corresponding increase in research productivity in terms of technology trends, resource generation, academic personnel potential and library holdings, and computer services. As the criteria for research awareness are fully met, the higher is the research productivity in terms of resource generation. The proper orientation on thrusts and priorities, implementation and dissemination of research outputs are systematically undertaken, the research productivity increases the potentials of the faculty members by facilitating the production of researches. The low values of beta coefficients however, may suggest that as the faculty becomes more competent and library holdings observed to a great extent the lower level of satisfaction they feel on some of the research components.

The result rejected the null hypothesis stating that research productivity is not influenced by the research awareness of the faculty members. There are four independent variables of research awareness: orientation; funding and other resource generation; implementation, monitoring evaluation and utilization of research results; and publication and dissemination that have positive and significant influences on the research productivity of the faculty members of the Laguna State Polytechnic University.

Testing the Moderate Influence of Research Culture on Research Productivity:Question 6:-Is the extent of research productivity singly or in combination moderately influenced by the level of research culture among the faculty?:-

The moderating variable research culture shows a significant relationship with the research productivity, $\mathrm{p}<.05$. 
Table 6:-Influence of Research Awareness on Research productivity.

\begin{tabular}{|c|c|c|c|c|}
\hline \multirow{3}{*}{$\begin{array}{l}\text { Independent Variable } \\
\text { (Research Culture) }\end{array}$} & \multicolumn{4}{|c|}{$\begin{array}{c}\text { Dependent Variable } \\
\text { (Research Productivity) }\end{array}$} \\
\hline & $\begin{array}{l}\text { Technology } \\
\text { Trends }\end{array}$ & $\begin{array}{l}\text { Resource } \\
\text { Generation }\end{array}$ & $\begin{array}{l}\text { Potential of } \\
\text { Academic } \\
\text { Personnel }\end{array}$ & $\begin{array}{c}\text { Auxiliaries, Library } \\
\text { Holdings, and } \\
\text { Computer Services }\end{array}$ \\
\hline & $\beta$ & $\beta$ & $\beta$ & $\mathrm{B}$ \\
\hline Constructive Culture & $.684 * *$ & $.447 * *$ & $.724 * *$ & $.539 * *$ \\
\hline \multicolumn{5}{|l|}{ Passive/Defensive Culture } \\
\hline Aggressive/Defensive Culture & & $.271 * *$ & & $.202 * *$ \\
\hline $\mathrm{R}-$ Square & .467 & .455 & .524 & .495 \\
\hline Adjusted R Square & .465 & .449 & .522 & .490 \\
\hline F-value & 176.372 & 84.413 & 221.555 & 97.971 \\
\hline Significance & $.000^{\mathrm{b}}$ & $.000^{\mathrm{c}}$ & .000 & $.000^{\mathrm{c}}$ \\
\hline Durbin-Watson & 1.843 & 2.047 & 1.828 & 1.859 \\
\hline
\end{tabular}

Legend: $N=203$, * Significant at $p<.05 * *$ Significant at $p<.01$

The data (Table 6) indicate that the research productivity in its qualitative aspects accounts for the $46.5 \%$ of the variance in technology trends (adjusted $\mathrm{R}^{2} 0.465$ ). The $\mathrm{F}$ statistics for the adjusted $\mathrm{R}^{2}$ is 176.372 and the associated $\mathrm{p}$-value is .000. It indicates that $\mathrm{p}<.05$; therefore, a statistically significant relationship exists between technology trends and research awareness at the 99.0 percent confidence level.

Constructive culture is characterized by norms for achievement, self-actualizing, humanistic-encouraging, and affiliative behaviors, which encourage members to interact with people and approach tasks in ways that will help them to meet their higher-order satisfaction needs. The Durbin-Watson test $(1.843<2.00)$ points out that the extracted parameters are not the only possible explanations for the development of the item research culture. The cooperation, pleasant relationship and the fulfillment of potential which characterize a constructive research culture are contributive to the increase in a level of research productivity in terms of technology trends.

Further, the regression results may imply that constructive culture with its concepts of achievement, selfactualization, affiliative and humanistic characteristics are the great influencers of research productivity not only in in technology trends $(\beta=.684, \mathrm{p}<.01)$ but as well as in other aspects of research as to resource generation $(\beta=.447$, Fvalue $=84.413, \mathrm{p}<.01)$; potentials of academic personnel $(\beta=.724$, F-value $=221.555, \mathrm{p}<.01)$; and auxiliaries, library holdings and computer services $(\beta=.539, \mathrm{~F}$-value $=97.971, \mathrm{p}<.01)$.

Noting further, that the research culture of aggressive/defensive is also a significant influencer of resource generation $(\beta=.271$, F-value $=84.413, \mathrm{p}<.01)$; and auxiliaries, library holdings and computer services $(\beta=.202, \mathrm{~F}$ value $=97.971, \mathrm{p}<.01)$ of the research productivity components.

The result rejected the null hypothesis stating that research productivity is not moderately influenced by the research culture of the faculty members. The positive characteristics of constructive culture and motivation of aggressive culture encourage and drive faculty members to approach tasks in forceful ways to protect their status and security, help them to meet their higher-order satisfaction needs, hence resulting to research productivity.

\section{Conclusions:-}

The findings show that research exists and is structured in the LSPU. The faculty members are aware that there are established research agenda and programs that they promote and develop.

The results revealed that the research culture of constructive, and aggressive/defensive have a moderating influence on the relationship between the research awareness and research productivity of the faculty members of the LSPU.

Constructive culture encouragedmembers to interact with people and approach tasks in ways that help them meet their higher-order satisfaction needs; to be in communication with their co-workers, and work as teams, rather than only as individuals. The significant influence of the constructive culture reveals that in LSPU where there is display of cooperation, pleasant relationship and fulfillment of individual potentials, the research productivity becomes higher. 


\section{Implications:-}

Results show that LSPU considers research as an opportunity for improvement. To mitigate this, the following activities should be deliberated: motivation and involvement of faculty and student researchers as presenters to international and national fora; setting up of Research and Development Extension performance ratings and standards; conducting RDE capability buildings, mentoring and write-shops, and putting up of an intellectual property (IP) policy and Manual on its proper place to advance copyrights, bar codes and patents, and implementing the research incentive system.

By 2020, it is hoped that the university will establish four operational research centers with an increased number of externally funded research programs and projects that aims to increase fund generation up to Php $40 \mathrm{million}(\$ 800$ $000+)$.

\section{Acknowledgments:-}

Our deepest appreciation to the help extended by the Research and Development Unit of the university in providing the funds for publication, and Faculty Members from the LSPU four campuses for their precious time in completing the questionnaire.

\section{Bibliography:-}

1. AACCUP Accreditation Handbook, 2014.Accrediting Agency for Chartered Colleges and Universities of the Philippines Accreditation Instrument for Area V- Research.

2. AACCUP, Basic Principles and Procedures in Accreditation Curricular Programs, 2000.

3. Aguinis, H., \& Henle, C. A. 2002. "Ethics in research. Handbook of research methods in industrial and organizational psychology.

4. Alghanim-Albamalt. 2011. "Research Productivity among Faculty members at Medical \& Health Schools in Saudi Arabia. Prevalence Obstacles and Associated Factors.

5. Almonte-Acosta, S. A. 2007. "Developing Research Culture in Philippine Higher Education Institutions: Perspectives of University Faculty Rose Marie Salazar-Clemeña, PhD Dean, College of Education De La Salle University-Manila.

6. Andal, Edilberto Z. 2010. "Research and Extension Programs of State Universities in CALABARZON: Perspectives in Establishing Standards for Program Effectiveness". Dissertation. Laguna State Polytechnic University, San Pablo City Campus.

7. Banayo, Agripina F. 2014. "Organizational Climate of the LSPU System, Job satisfaction of the Teaching Staff and Institutional Performance: Bases for Quality Management”. Dissertation. Laguna State Polytechnic University, San Pablo City Campus.

8. Callo, Eden C. 2005. "Organizational Climate and Performance of Selected State Universities and Colleges". Dissertation, TUP, Manila.

9. Calma, A. 2010. "Funding for Research and Research Training and Its Effects on Research Activity: The Case of the Philippines. Asia-Pacific Education Researcher.

10. Calmorin, Laurintina P and Calmorin, Melchor A. 2000. "A Methods of Research and Thesis Writing. Quezon City: Rex Printing Company, Inc.

11. Campbell, B. M., \& Sayer, J. 2003. "Integrated Natural Resource Management: Linking Productivity, the Environment and Development. CABI.

12. Cheetham, A. 2007. "Growing a research culture. University of Western Sydney, Address.

13. Constitution of the Philippines. 1987

14. Cooke, R. A., \& Szumal, J. L. 2000. "Using the Organizational Culture Inventory to understand the operating cultures of organizations. Handbook of organizational culture and climate".

15. Creswell, J. W. 2003. "Faculty Research Performance: Lessons from the Sciences and the Social Sciences. ASHE- ERIC Higher Education Report No. 4, 1985. Association for the Study of Higher Education, One Dupont Circle, Suite 630, Department PR-4, Washington, DC.

16. Cuenca, J. S. 2011. "Efficiency of state universities and colleges in the Philippines: A data envelopment analysis (No. DP 2011-14).

17. Deshpande, R., \& Webster Jr, F. E. 1989. “Organizational culture and marketing: defining the research agenda. The Journal of Marketing.

18. Dr. Tseen Khoo. 2015. "Myths about research cultures. Research cultures are complex and easily skewed. This is why "slowing the increase for university funding has significant, long-term consequences. | LinkedIn. (n.d.). 
Retrieved August 6, 2015, fromhttps://goo.gl/dHEtUVc

19. Eppard, R. G. 2003. "Transformational and transactional leadership styles as they predict constructive culture and defensive culture.

20. Geronimo, Vilma. 2014. "Indicators of Research Capability of State Universities and Colleges in Calabarzon": Dissertation. Southern Luzon State University- Lucban, Quezon.

21. Gonsalves, J. F. 2005. "Participatory Research and Development for Sustainable Agriculture and Natural Resource Management: Understanding participatory research and development. IDRC.

22. Goodall AH. 2010. "Why Socrates should be in the Boardroom in Research Universities. Research and Occasional Paper Series, http://cshe.berkeley.edu/why-socrates-should-be-boardroom-research-universities $(10 / 3 / 2013)$.

23. Greenspan, Alan, and Richard M. Rosan. 2003. "The Role of Universities Today: Critical Partners in Economic Development and Global Competitiveness." UC's Contributions to Economic Growth, Health, and Culture. http://klamath-vhost.ucop.edu/itstartshere/report/role_today.pdf(11/2/2013)

24. Hill, R. 1999, July. "Revisiting the term "research culture". In HERDSA Annual International Conference.

25. http://www.topuniversities.com/node/4468/ranking-details/asian-university-rankings/2013 (11/2/2013).

26. Jonassen, D. H., \& Rohrer-Murphy, L. 1999. "Activity theory as a framework for designing constructivist learning environments. Educational Technology Research and Development.

27. LSPU Annual Report 2014.

28. LSPU Research Incentive System. BOR Resolution No. 1210, Series of 2015

29. Meek, V. I. N. C. E. N. T., \& Suwanwela, C. (Eds.). 2016. "Higher education, research, and knowledge in the Asia-Pacific region. Springer.

30. Morshidi, S., Sadullah, A. F., Komoo, I., Lie, K. Y., Meriam, N. N., Norzaini, A., ... \& Wong, W. 2010. "Research and collaboration in an expanding higher education market in the Asia-Pacific: The experiences of Malaysian universities. Globalization and tertiary education in the Asia-Pacific: The changing nature of a dynamic market.

31. Padua RN 2003. "International Higher Education Quality Assurance Practices: Situating Philippine System, J. Philippine Higher edu. Quality Assurance, Vol.1, No.1. Manila: AACCUP

32. Parekh, S., Hooper, L., Loke, Y. K., Ryder, J., Sutton, A. J., Hing, C., ...\& Harvey, I. 2010. "Dissemination and publication of research findings: an updated review of related biases. Prepress Projects Limited.

33. Placino, Merlina J. 2014. "Administrative Effectiveness as Influenced by Work Values, Managerial Functions and Decision-Making Responsibilities Among Public Secondary School Heads in Batangas Province" Dissertation. Laguna State Polytechnic University.

34. Quacguarelli Symond University rankings 2013

35. Quimbo, M. A. T., \& Sulabo, E. C. 2014. "Research productivity and its policy implications in higher education institutions. Studies in Higher Education, 39(10), 1955-1971.

36. R \& D Guidelines and Procedures Book No. 01, Series 2015. Laguna State Polytechnic University-San Pablo City Campus.

37. Rauhvargers A. 2011. Global University Rankings and their Impacts, Brussels: EUA

38. Rosenbloom, J. L., Ginther, D. K., Juhl, T., \& Heppert, J. A. 2015. "The Effects of Research \& Development Funding on Scientific Productivity: Academic Chemistry, 1990-2009. PloS one, 10(9), e0138176.

39. Salvador, Nelia T. 2005. "Organizational Factors and Performance in Research, Extension Services and Production of Selected SUCS in Region IV-A". Dissertation. Technological University of the Philippines.

40. Shamoo A and Resnik D. 2003. "Responsible Conduct of Research". (New York: Oxford University Press).

41. Sunder, S. 2008. "Building research culture. China Journal of Accounting Research, 1, 83-85.

42. Tagala, Lorena. 2011. "Level of Research Awareness and Culture Among Faculty of Higher Education Institutions in Calamba City: Input to Productivity": Dissertation. Laguna State Polytechnic University.

43. Versano, Dolores D. 2008. "Predictors of Faculty Creativity and Performance in Research, Extension Services, and Production in Laguna Polytechnic University System". Dissertation. Technological University of the Philippines,

44. Villenas, Benilda N. 2008. "Creating and Maintaining a Research Culture in Institution of Higher Learning: The Continuing Journey of Four HEIs". Dissertation. De La Salle University-Manila.

45. Wellington, J and Szczerbinski M. 2007. "Research Methods for the Social Sciences. Continuum International Publishing Group. 